\title{
EDUCACIÓN EMOCIONAL EN LA FORMACIÓN DOCENTE: CLAVE PARA LA MEJORA ESCOLAR
}

\section{Emotional education in teachers training: a key for school improvement}

\author{
Berenice Pacheco-Salazar ${ }^{1}$
}

Recibido: 13/7/2016 • Aprobado: 12/12/2016

\begin{abstract}
Resumen
Este ensayo presenta reflexiones, desde los planteamientos teóricos actuales de especialistas e investigadores como Goleman, Bisquerra, Mayer, Royo, Alonso, Vaello, Trianes y Baene, sobre la importancia de la educación emocional en tres aspectos principales: la prevención primaria de la violencia escolar, el fomento de la convivencia y la mejora de la calidad de la educación. Se concluye que es necesario que la educación emocional sea apreciada como un componente clave en el desarrollo profesional docente.
\end{abstract}

Palabras clave: educación emocional; inteligencia emocional; formación docente; violencia escolar; convivencia escolar.

\begin{abstract}
This article introduces reflections, about current theoretical approaches from specialists and researchers such Goleman, Bisquerra, Mayer, Royo, Alonso, Vaello, Trianes and Baene, regarding the importance of emotional education in three main areas: the primary prevention of school violence, to foster a positive school climate and the improvement of the quality of education. The author concludes that the emotional education should be a key component in the professional development of teachers.
\end{abstract}

Keywords: emotional education; emotional intelligence; teachers training; professional development of teachers; school violence; school climate.

1. Profesora del INTEC. Correo electrónico: bereniceps@ gmail.com 


\section{Introducción}

El objetivo de todo proceso educativo es contribuir al desarrollo integral de las personas. Para lograrlo, los centros educativos han de ser espacios abiertos al diálogo, a la participación, a la creatividad y a la diversidad, es decir -en palabras de Royo (2013a)centros emocionalmente inteligentes. Para Del Rey y Ortega (2001), es fundamental que la escuela sea un entorno propicio para la construcción de una sana vida emocional en la que el estudiantado

aprenda a expresar sus emociones, a tomar conciencia de sus sentimientos y asumir actitudes de respeto hacia las emociones de los otros (...) a desarrollar la empatía, o la capacidad de ponerse cognitiva y sentimentalmente en el lugar del otro y percibir sus sentimientos. (p. 33)

Sin embargo, la escolarización tradicional se ha centrado en la memorización de información y en el control de la conducta, dejando muchas veces de lado el hecho de que en todo proceso humano, incluido el educativo, está implicada la vida afectiva y que, por tanto, el cuerpo docente siempre influye, habiéndoselo propuesto o no, en las dimensiones personales y relacionales de sus estudiantes. La persistencia de estructuras de participación y gestión autoritarias, las dificultades de aprendizaje, el fracaso escolar, la indisciplina y la propia violencia escolar evidencian la necesidad de trabajar en el desarrollo de la inteligencia emocional desde los centros educativos.

La educación emocional se reconoce como una estrategia de prevención primaria de la violencia escolar y de construcción de una cultura escolar armónica y positiva. Por tanto, es un pilar fundamental a ser considerado en el desarrollo profesional docente.

\section{Educación emocional: aproximación a una definición}

Las emociones son el origen y el motor de nuestras acciones; son las que definen cómo accionamos -o no- y desde cuáles motivaciones. Son la clave de nuestra interacción con el entorno y de nuestro propio conocimiento y crecimiento personal.

Mayer y Salovey (1997) definen la inteligencia emocional como aquella basada en el uso adaptativo de las emociones, lo que implica la habilidad para percibirlas, valorarlas, comprenderlas, regularlas y expresarlas con precisión, para así promover el crecimiento afectivo e intelectual. En palabras de Goleman (1998), se entiende como la capacidad de distinguir los sentimientos internos que emergen en las comunicaciones interpersonales y poder canalizarlos evitando actuar de manera impulsiva.

Para Bisquerra (2005) y Bisquerra y Pérez-Escoda (2014), la educación emocional o 'desde dentro'es un proceso educativo permanente que busca aumentar el bienestar personal y social a través del desarrollo de la capacidad de comprender las propias emociones, de expresarlas asertivamente, de prevenir los efectos nocivos de las negativas y tener la habilidad para generar las positivas, así como de sentir empatía hacia uno mismo y las demás personas.

La educación emocional, como vía para el desarrollo de la inteligencia emocional, potencia el crecimiento integral de personas capaces de convivir armónicamente consigo mismas y su entorno, y de enfrentar con asertividad las diversas situaciones y obstáculos que se le presenten en el quehacer cotidiano del aula y de la vida (Longobardi, 2002; Horno, 2004; Funes, 2006; Navarro, 2013; Redorta, Obiols \& Bisquerra, 2014). 


\section{Implicaciones de la educación emocional}

Vaello (2009), en su libro El profesor emocionalmente competente. Un puente sobre "aulas" turbulentas, expresa que las competencias socioemocionales son un "conjunto de habilidades que permiten interactuar con los demás o con uno mismo de forma satisfactoria" (p. 19) y que, por tanto, el cuerpo docente

ha de asumir que debe ser un entrenador de competencias de los demás y de él mismo, pues no está exento de carencias que puede subsanar en campos tan decisivos como la autoestima, resiliencia, automotivación, respeto, persistencia, autocontrol, responsabilidad, fuerza de voluntad o empatía (...). El profesor emocionalmente competente afronta los problemas en mejores condiciones y ayuda a crear un clima positivo que constituye un lecho sobre el que se puede asentar más confortablemente el proceso enseñanza-aprendizaje. (p. 11)

Para Goleman (1998), la inteligencia emocional implica la autoconciencia y la autogestión de las propias emociones, la automotivación y el desarrollo de la empatía en las relaciones sociales. Para Beane (2006), la educación emocional requiere de la formación para la resolución pacífica de conflictos, la gestión de la ira, el manejo del estrés, la atención a la diversidad y el desarrollo de habilidades sociales.

Otros autores incorporan en su comprensión de la educación emocional la importancia del desarrollo de la escucha activa (Villaoslada \& Palmeiro, 2006), del sentido del humor (Gutiérrez \& Prieto, 2002), de la autoestima (Trianes \& Morales, 2011), la flexibilidad (Alonso, 2011), el autoconocimiento y la automotivación (Vaello, 2009), la regulación y la autonomía emocional (Redorta et al., 2014), la asertividad y la empatía (Córdoba, Romera y Ortega, 2008) y la afectividad entendida como la tonalidad emocional que acompaña los vínculos interpersonales (Ortega \& Mora-Merchán, 1996).

Por su parte, Alonso (2011) propone el desarrollo de la pedagogía de la interioridad como respuesta a la necesidad de educar emocionalmente desde el ámbito escolar.

Educar la interioridad es enseñar a mirar hacia dentro (...), es ayudar a desarrollar aquellas facultades que capacitan al ser humano para acceder a una experiencia mucho más amplia de lo que la razón le permite (...), es educar para aprender a fluir con la vida. La interioridad es la posibilidad que todos tenemos de mirar hacia dentro, de ser y de crecer como personas, de ser lo que somos en lo profundo de nosotros mismos. Tiene que ver con el reconocimiento personal, con el descubrimiento de nuestro ser más íntimo y con el vivir la relación con todo nuestro entorno. (pp. 55-56)

La pedagogía de la interioridad, como educación para ser y convivir, busca favorecer actitudes para "aprender a aprender" como son la flexibilidad, la apertura mental, la capacidad intuitiva, la sabiduría interior y la posibilidad expresiva. La autora plantea que tres grandes pilares principales sostienen la pedagogía de la interioridad: la conciencia y la regulación emocional, la espiritualidad, y el desarrollo de valores como son la autonomía, la confianza, la honestidad y el respeto.

Desarrollar una convivencia educativa armónica implica, en palabras de Alonso (2011), que el personal docente tenga apertura a sus propias vivencias y sentimientos, cultive la capacidad de escucha y asombro, desarrolle la curiosidad y reconozca sus propias fortalezas y límites. 


\section{Inteligencia emocional: clave para la mejora educativa}

La violencia escolar es reconocida como un obstáculo para la mejora de la calidad educativa, para el logro de los aprendizajes y para el sano desarrollo de estudiantes y docentes (Abramovay, 2005; DíazAguado, 2005; Perrenoud, 2008).

Comprender sus causas desde su propia complejidad, requiere de una mirada atenta al contexto familiar y comunitario en el que se desarrolla, así como también a la carencia de educación emocional de la cual todas y todos -en mayor o menor medida- padecemos. Junto al abuso de poder, la imposibilidad de reconocer y regular autónomamente las emociones se encuentra como núcleo central de las situaciones de violencia que ocurren en los centros educativos.

Este analfabetismo emocional (Trianes \& García, 2002) provoca que el abordaje de la violencia escolar usualmente se centre en la conducta observable lo cual es insuficiente pues, como señala Carpena (2013), "atender la conducta sin atender la emoción es como atender la fiebre sin querer saber su causa" (p. 74). De este modo, la educación emocional se constituye en una piedra angular para el impulso de estrategias integrales para la atención y prevención de la violencia en el ámbito educativo. Para Hernández y Jaramillo (2005), es imperativo que se asuma una concepción de la enseñanza y el aprendizaje centradas en la formación integral de las personas, donde se preste atención al desarrollo social y afectivo de cada individuo.

Como seres humanos, somos lo que sentimos, nuestras motivaciones, nuestros proyectos de vida y nuestras aspiraciones. En un contexto donde muchas veces se pone el énfasis en los resultados, en el rendimiento evaluable y en la competitividad, cobra sentido recuperar el sentido de la educación como relación afectiva y humanizante. Se ha determinado que el sano desarrollo emocional y afectivo de las y los docentes incide en la mejora de la convivencia escolar (Navarro, 2013), y que se constituye en la base de todas las competencias socio-emocionales (Horno, 2004) y en la cohesión de todas las competencias docentes (Royo, 2013b).

La educación emocional propicia la convivencia escolar armónica y positiva, y el establecimiento de relaciones sociales empáticas y horizontales. De esta manera, se crean condiciones para la participación y el trabajo colaborativo entre estudiantes y docentes. El aprender a ser, a aprender y a con-vivir juntos, así como el sentirnos competentes, se generan y gestionan desde lo emocional y lo motivacional. La motivación es reconocida como un componente primordial en la construcción de procesos efectivos de enseñanza-aprendizaje.

Dicho todo lo anterior, es posible visualizar la relación casi inherente que existe entre la educación emocional y los procesos de mejora de la calidad educativa. Planteo que la educación emocional ha de formar parte de los objetivos y la cotidianidad de los centros educativos. Debido a que parte importante de los años de nuestras vidas suelen ocurrir en el contexto escolar, los centros educativos se constituyen en un espacio privilegiado para la consecución de este propósito. Se demanda, pues, de la construcción de nuevos sentidos y prácticas educativas donde, entre otras cosas, los y las docentes nos asumamos como "educadores emocionales" (Bisquerra, 2005, p. 2).

\section{Maestras y maestros emocionalmente inteligentes: reto para la formación docente}

La educación emocional tiene que ser entendida como un proceso que ha de trabajarse de manera permanente y consciente, y a través de metodologías activas y participativas. No se trata de generar y transmitir información teórica sobre la temática, sino de construir experiencias de autoconocimiento y convivencia que fomenten la inteligencia emocional 
permeando las relaciones cotidianas intergeneracionales, pero también los estilos, los ritmos y las metodologías de los procesos de enseñanza - aprendizaje.

El trabajo con cuentos, escritura creativa, mandalas y diarios reflexivos son algunas estrategias que posibilitan la educación emocional. Acciones aparentemente tan simples como hablar de cómo nos sentimos de manera sincera y horizontal, sin juzgar ni sancionar, van generando un clima de aula que favorece la inteligencia emocional.

Es necesario que la educación emocional sea considerada un fundamento básico en la formación inicial y el desarrollo profesional docente en República Dominicana. Fomentar en las y los docentes competencias socioemocionales contribuye a deconstruir la pedagogía adultocéntrica y a favorecer la formación integral de seres humanos con mayor creatividad, autonomía, empatía, sana afectividad y sentido de bienestar. Esto, por supuesto, no solo beneficia al docente en su rol de enseñante y como persona, sino que también favorece al estudiantado y a los propios procesos de mejora educativa, tal y como he expresado antes.

La educación emocional propicia, además, la formación de docentes con mayor y mejor preparación para afrontar los diversos y complejos retos de la tarea de educar. Junto a esto, se reconoce también como un factor determinante en la reducción y la prevención del síndrome de burnout en el cuerpo docente, y en el mantenimiento y fortalecimiento de su vocación profesional.

En ese sentido, Extremera y Fernández-Berrocal (2004) resaltan que "unos adecuados niveles de inteligencia emocional ayudan a afrontar con mayor éxito los contratiempos cotidianos y el estrés laboral al que se enfrentan los profesores en el contexto educativo" (p. 1). Para Marchesi (2007), "el bienestar docente es una condición necesaria para la buena actividad educativa" (p. 141) y en esto la inteligencia emocional desempeña un rol relevante.

\section{Referencias}

Abramovay, M. (2005). Violencia en las escuelas: un gran desafío. Revista Iberoamericana de Educación, 38, 53-66.

Alonso, A. (2011). Pedagogía de la interioridad. Aprender a "ser" desde uno mismo. Madrid: Narcea Ediciones.

Beane, A. (2006). Bullying. Aulas libres de acoso. Barcelona: Editorial Graó.

Bisquerra, R. (2000). Educación emocional y bienestar. Barcelona: Editorial Praxis.

Bisquerra, R. (2005). La educación emocional en la formación del profesorado. Revista Interuniversitaria de Formación del Profesorado, 19(3), 95-114

Bisquerra, R. y Pérez-Escoda, N. (2014). Educación emocional para la prevención. En R. Bisquerra (Coord.). Prevención del acoso escolar con educación emocional (pp. 97-115). Bilbao: Editorial Desclée de Breouwer.

Carpena, A. (2013). Crecimiento emocional en el aula. En P. Darder (Coord.). Aprender y educar con bienestar y empatía. La formación emocional del profesorado (pp. 69-101). Barcelona: Ediciones Octaedro.

Córdoba, F., Romera, E. y Ortega, R. (2008). ¿Cómo construir la convivencia en un centro educativo? Revista Padres y Maestros, 313, 30-32.

Del Rey, R. y Ortega, R. (2001). El Programa de ayuda entre iguales en el contexto del Proyecto Sevilla Antiviolencia Escolar. Revista de Educación, 326, 197-310.

Díaz-Aguado, M. (2005). Por qué se produce la violencia escolar y cómo prevenirla. Revista Iberoamericana de Educación, 37, 17-47. 
Extremera, N. y Fernández-Berrocal, P. (2004). La importancia de desarrollar la inteligencia emocional en el profesorado, Revista Iberoamericana de Educación, 33 (8). 1-10

Funes, S. (2006). Hacia un mayor conocimiento de la mediación y el tratamiento de conflictos. En J.C. Torrego (Coord.) Modelo integrado de mejora de la convivencia. Estrategias de mediación $y$ tratamiento de conflictos. Barcelona: Editorial Graó.

Goleman, D.(1998) La inteligencia emocional, Por qué es más importante que el cociente intelectual. México: Javier Vergara.

Gutiérrez, F. y Prieto, D. (2002). La mediación pedagógica. Apuntes para una educación a distancia alternativa. Valencia, España: L'Ullal Edicions.

Hernández, G. y Jaramillo, C. (2005). Tratar los conflictos en la escuela sin violencia. Serie de Cuadernos de Educación No Sexista, No. 14. Madrid: Instituto de la Mujer, Ministerio de Educación, Cultura y Deporte.

Horno, P. (2004). Educando el afecto. Reflexiones para familias, profesorado, pediatras. Barcelona: Editorial Graó.

Longobardi, G. (2002). III. Emociones en el aula. Una cuestión de gracia. En A. Eccelli (Coord.) El perfume de la maestra en los laboratorios de la vida cotidiana (pp. 51-59). Barcelona: Icaria Editorial.

Marchesi, A. (2007) Sobre el bienestar de los docentes. Competencias, emociones y valores. Madrid: Alianza Editorial.

Mayer, J. y Salovey, P. (1997). What is emotional intelligence. En Salovey, P. y Sluyter, D. (Eds.). Emotional development and emotional intelligence: Educational implications. (pp. 3-31). New York: Basic Books.

Navarro, J. (2013). La Educación Emocional como estrategia para fortalecer la convivencia escolar en el aula. Recuperado de http://www.cives.cl/ocs/index.php/cives/5cives/paper/viewFile/58/73

Ortega, R. y Mora-Merchán, J. (1996). El aula como escenario de la vida afectiva y moral. Cultura y Educación, 3, 5-18.

Perrenoud, P. (2008). Diez nuevas competencias para enseñar. Tiempo de Educar, 9(17), 153-159.

Redorta, J., Obiols, M. y Bisquerra, R. (2014). Emoción y conflicto. Aprenda a manejar las emociones. Barcelona: Paidós.

Royo, M. (2013a). Centros emocionalmente inteligentes. En P. Darder (Coord.). Aprender y educar con bienestar y empatía. La formación emocional del profesorado (pp. 45-67). Barcelona: Ediciones Octaedro.

Royo, M. (2013b). Nuevas perspectivas en la formación inicial del profesorado. En P. Darder (Coord.). Aprender y educar con bienestar y empatía. La formación emocional del profesorado (pp. 143160). Barcelona: Ediciones Octaedro.

Trianes, M.V. y García, A. (2002). Educación socio-afectiva y prevención de conflictos interpersonales en los centros escolares. Revista Interuniversitaria de Formación del Profesorado. (44), 175-189.

Trianes, M.V. y Morales, F. (2011). Pautas de intervención para la mejora de la convivencia en los centros educativos. En A. García (Ed.). Violencia escolar $y$ de género. Conceptualización y retos educativos (pp. 107-115). Huelva, España: Universidad de Huelva.

Vaello, J. (2009). El profesor emocionalmente competente. Un puente sobre "aulas" turbulentas. Barcelona: Editorial Graó.

Villaoslada, E. y Palmeiro, C. (2006). Formación de los equipos de mediación y tratamiento de conflictos. En J. C. Torrego (Coord.) Modelo integrado de mejora de la convivencia. Estrategias de mediación $y$ tratamiento de conflictos (pp. 69-108). Barcelona: Editorial Graó. 


\section{Datos de filiación}

Berenice Pacheco-Salazar es doctora en Educación por la Universidad de Sevilla. Licenciada en Psicología con maestría en Género y Desarrollo, del Instituto Tecnológico de Santo Domingo (INTEC), donde se desempeńa como docente e investigadora. Especialista en educación de la Organización de Estados Iberoamericanos para la Educación, la Ciencia y la Cultura (OEI).

Es autora y co-autora de diversas publicaciones sobre las temáticas de promoción de la lectura, derechos humanos, violencia escolar y educación para la ciudadanía. Es poeta, con dos libros publicados y reconocimientos en Argentina y Perú.

Correo electrónico: bereniceps@gmail.com 